\title{
Planning and Research of Integrated Test System for Rail Transit
}

\author{
Lian Yiping \\ Xi’an Railway Vocational \& Technical Institute, School of Transportation, Xi'an, Shaanxi, 710014
}

Keywords: Rail Transit, Integrated System, Construction Plan

\begin{abstract}
In recent years, with the rapid development of social economy and the deepening of economic restructuring, a more convenient, safer and less consumption mode of transportation has become an inevitable trend of social transportation development. Because of its all-weather, pollution-free and small area, railway has gradually become the key planning and development vehicle in our country. This paper studies the planning and design of rail transit comprehensive test system, and has certain strategic value for promoting the rapid development of efficient transportation system that runs through the mainland's economy and culture.
\end{abstract}

\section{Introduction}

The innovation of rail transit technology and equipment is an important supporting force for the rapid development of China's railway industry. With the continuous development of modern information technology and the level of China's industrial automation continues to improve China's rail transportation equipment and facilities in fully absorb the essence of technology and methods of domestic and international rail transport development has made great progress, to create an important equipment and technical means to promote the leapfrog development of China Railway industry continuously; break the rail transportation to the national economy long-term, sustainable development brings high speed, stability, safety and other constraints bottleneck, provide a powerful force for the steady development of transportation and transformation of China's economic structure of all walks of life [1-2]. Rail transportation comprehensive test system is an important part of the rail transportation, rail transportation as a public test platform of new technology and equipment put into operation, the important responsibility assessment test for the railway traffic, is to improve the level of China's pioneering efforts to transport rail transport.

\section{Research Goal of Integrated Test System for Rail Transit}

The research goal of rail transportation comprehensive test system, including two points, one is designed for China's rail transit new technology, new methods and new equipment with high quality, high precision, performance test platform, improve the safety guarantee for the reform and operation of rail transit in China; the establishment of a new technology and new rail transportation as to the equipment innovation center and talent development base, with deep research and development team and independent intellectual property development industry chain support for the rapid and sustainable development of urban rail transit in china [3]. At present, all countries in the world have invested a lot of manpower, material and financial resources to the construction of rail transportation comprehensive test center, to provide strategic support the prosperity and development of domestic rail transportation, the construction of the largest, the most abundant content of the experimental study on rail transportation comprehensive test center including the German Vikberg - Wilden Lasz test center the United States, the transportation technology center and the French transport research center [4-5]. In Germany Vikberg - Wilden Lasz test center as an example, establishment and operation of the test center can simulate all kinds of extreme scenarios and a full range of test run on rail transportation safety, stability, comfort, all equipment and technology for various types of rail vehicles and rail traffic system, such as rail transportation the network communication, vehicle track, track subgrade debugging and test precision, shorten the test period and test cost of rail transportation, reducing the German city rail transit operation cost, meet 
the urgent needs of rapid rail transit in response to the market.

Through detailed analysis of the functions and test contents of the internationally advanced rail transit comprehensive test system, we can provide comprehensive guidance for the research objectives and research and development business of our rail transit test system.

\subsection{Research on integrated rail vehicle system based on integrated rail transit test system}

As an important carrier of rail transportation system, the rail vehicle is embedded with a large number of parts and equipment facilities. After testing and testing all the components, we need to carry out the integrated test of the whole rail vehicle system, so as to ensure the integrity, safety and stability of the integrated system. Based on the integrated rail transit test system, all the key components in the vehicle system and the whole vehicle can be constructed and tested in a full and fine way [6]. Timely discover the defects of components and problems existing in structural integration and provide experimental data support for improvement and adjustment of integrated system defects to improve the reliability and service life of vehicle integrated system operation.

\subsection{Research on low power walking part of vehicle based on integrated rail transit test system}

In the course of the vehicle, a certain size of friction will be produced between the track and the rail. The existence of friction is not only a driving force of the roller, but also closely related to the wear condition of the wheel, the noise emitted by the traffic, the bump of the vehicle, and the riding comfort of passengers. Rail transit system based on the test, it can simulate various extreme environmental conditions, such as weather conditions of low temperature and high temperature, heavy rainfall and various types of vehicles and tracks, used to study the existence of different design of rail transit system under extreme conditions of problem [7-8]. This provides an experimental analysis basis for the optimization of rail transit system, which can effectively reduce the wear rate of vehicle rollers, reduce vehicle maintenance costs, and ensure smooth operation of rail transit system.

\subsection{Research on adaptive anti-skid antiskid system of vehicle based on integrated rail transit test system}

The adaptive antiskid air defense of vehicle is an important test content of the trial operation of the vehicle. In the extreme conditions under different braking efficiency, vehicle idling, wheel wear, wheel slip and skid index test and quantitative research, which can effectively control the vehicle sliding and idling, the vehicle running suitable weather conditions in the comprehensive evaluation of the threshold. Based on the rail transit comprehensive test system to simulate different weather conditions, the longitudinal impulse degree, wheel braking efficiency and wheel idle speed under different conditions are important for enhancing the safety of rail vehicle travel.

\subsection{Research on comprehensive measures for low noise vehicles based on integrated rail transit test system}

Low noise travel is an important condition for rail transit system, noise pollution can reduce the running noise to the surrounding environment, but also can reduce the noise of passenger rail traffic, ensure quiet and comfortable travel environment, reduce the noise of the damage. Based on the integrated rail transit test system, the noise of the vehicle can be measured accurately, and the sound source of the noise is positioned in two dimensions [9]. The location of the noise volume exceeding the standard needs to be adjusted and improved to ensure that the operation noise of rail transit is controlled within the international noise standard.

\subsection{Research on computer simulation test based on integrated test system of rail transit}

Computer simulation is an important basic experiment of new technology and new equipment test. With the help of computer's fast computing power and 3D simulation ability, we can realize the simulation of real environment in computer system. The simulation of different environmental conditions under simulated environment can greatly reduce the consumption of manpower, material and financial resources caused by actual test environment, and also avoid all kinds of risks produced 
during the actual test [10-11]. Based on the comprehensive test system of rail transit, 3D reconstruction of real test scenes can be realized, and the accuracy of simulation results can be ensured by establishing reasonable test plans and building near real simulation environment.

\section{Design Principle of Integrated Test System for Rail Transit}

Based on the above analysis of rail transit comprehensive test system, the rail transit comprehensive test system has many test projects, involving many disciplines and many fields. Interdisciplinary integration of multidisciplinary makes the design of integrated rail transit test system more complex and difficult. Therefore, during the design process of rail transit comprehensive test system, we should strictly abide by the following design principles, so as to ensure that the comprehensive test system of rail transit achieves the desired goal.

\subsection{Systematic}

The test items and research contents involved in the rail transit comprehensive test system cover many disciplines and specialties, such as communication, logistics, bridge and culvert, railway management, physics, ecology and so on. In the design process of the comprehensive test system should follow the principle of system, one can realize the full range of the subject fusion and fine quasi quantitative test of test items, on the other hand should also take into account economic research project testing and the impact on the ecological environment [12]. Through the control of the whole life cycle of rail transit test process and experimental details, we design a comprehensive test system to maximize the economic benefits, social benefits and ecological benefits, so as to build a scientific and reasonable public platform for comprehensive tests.

\subsection{Generality}

The test object of rail transportation comprehensive test system for various types, including various types of vehicles, rail, rail transportation traction equipment parts and equipment and facilities, to test the business process is relatively complex, so in the design and planning of rail transportation comprehensive test system should be considered when the general public test platform. The base of the investigation in the planning and design of the international advanced rail transportation comprehensive test system, combined with the experimental research, design a highly integrated test system of sharing and universality, maximize all kinds of test environment, test equipment, test reuse of experimental instruments, in order to reduce the comprehensive test system rail transportation facilities investment [13].

\subsection{Reliability}

Besides comprehensive and precise test platform for rail transit components, rail transit comprehensive test system also needs to provide highly automated fault detection device for all test contents. The real-time monitoring and real-time operation parameters are obtained through operation of test equipment, with the help of signal feature analysis and intelligent fault diagnosis of equipment operating parameters of the computer simulation technology, automatic fault diagnosis and repair test equipment facilities to provide a more accurate analysis of fault data support, improve the reliability test system.

\section{Construction Scheme of Integrated Test System for Rail Transit}

\subsection{Construction plan of test line}

The construction of test line is a comprehensive scientific research basis for comprehensive research and development of railway locomotive and rolling stock, railway building, railway electrification, communication and signal, passenger and freight transportation, special transportation, driving safety, subway and urban rail vehicles. Considering the compatibility test of rail transit system such as large railways and urban rail transit, we can build internal loop test line, outer loop test line and high-speed test line respectively, so as to meet the successful completion of 
different test projects and the successful completion of test objectives. Among them, the construction of inner loop test line should be independent annulus, constitute an independent test system and separate from other test lines, so as to ensure the independence of test items. The construction plan of high speed test line takes into account the quasi high speed test of internal combustion engine traction, the quasi high speed traction by electric locomotive and high-speed comprehensive test [14]. It can be built according to the highest speed of $350 \mathrm{~km} / \mathrm{h}$. The construction of outer ring test line should reflect the actual operation line condition. Therefore, its construction plan can be designed with reference to the actual operation track line year by year, providing more realistic experimental conditions for the actual operation and application of railway equipment and facilities.

\subsection{Construction scheme of communication network}

The construction of the communication network of rail transit system can provide electrical test process and communication information transmission channel with reliable test, improve the rail transit test process repeated laying of cables brought manpower and material resources waste phenomenon, has important significance to improve the comprehensive construction effect test system. There are two schemes for the construction of the communication network of the rail transit system: the wired communication and the wireless communication. Through the wired communication in the vicinity of the corresponding test line railway cable to realize the sharing and transfer of test data; wireless communication can be set up in the wireless base station test center, to realize the communication and transmission of test data with full coverage of the public network or special railway network.

\subsection{Construction scheme of various experimental laboratory}

The National Laboratory of rail transit includes the laboratory of locomotive and rolling stock, communication signal laboratory, engineering laboratory and transportation logistics laboratory, etc. Together with the railway test line, the test platform of rail transit comprehensive test system is constituted, which integrates production, learning and research, and bridges between theoretical research, technological development and application. In the vehicle laboratory as an example, the vehicle is the main test items of laboratory standard test and research project, a complete system to carry out the test vehicle type and durability test, so the required vehicle laboratory equipment and professional test environment are all needed for the design and construction of the whole surface, in order to achieve the test requirements.

\section{Conclusion}

Strengthening the research of rail transit comprehensive test system helps to break the monopoly position of foreign advanced equipment and technology in China's rail transit industry, and effectively improve the development level and independent R \& D ability of China's rail transit. It will provide an important basic platform support for training our rail transit advanced technology and talents, and building our own rail transit technology and equipment with independent intellectual property rights.

\section{References}

[1] Tang T, Dai K, Zhang Y, et al. Field test results analysis in urban rail transit train ground communication systems of integrated service using LTE-M[C]// IEEE, International Conference on Intelligent Transportation Systems. IEEE, 2016:2017-2021.

[2] Wang B, He F. Urban Rail Transit Network Planning: A Perspective of Integrated Transport System Development[J]. Urban Rapid Rail Transit, 2016.

[3] Tong X, Wu Z. Research on the Evaluation Index System of the Integration of Rail Transit and Conventional Public Transit[J]. 2015. 
[4] Li C B, Zhang Y, Guo R X. Research on the Common Rail Transport System Building in Integration System of Urban Rail Transit in Hohhot[J]. Applied Mechanics \& Materials, 2014, 599-601:599-602.

[5] Wang Y, Pan X, Su S, et al. Integrated Line Planning and Train Scheduling for an Urban Rail Transit Line[J]. Transportation Research Record Journal of the Transportation Research Board, 2016, 2540(2540):66-75.

[6] Pan H, Li J, Shen Q, et al. What determines rail transit passenger volume? Implications for transit oriented development planning[J]. Transportation Research Part D Transport \& Environment, 2017, 57:52-63.

[7] Li W, Liu L, Fan J. Planning and Practice: Integration of Suzhou Rail Transit with Ground Transportation[J]. Urban Rapid Rail Transit, 2016.

[8] Wu Q. The Research of Urban Rail Transit Integrated Automation System Based on Cloud Computing[C]// International Conference on Machinery, Materials and Computing Technology. 2016.

[9] Tong X, Wu Z. Research on the Evaluation Index System of the Integration of Rail Transit and Conventional Public Transit[C]// Cota International Conference of Transportation Professionals. 2015:2340-2351.

[10] Wei S, Chu D. Research Review of Rail Transit and Urban Space Integration Development[J]. 2015.

[11] Qian C, Xin M, Wang L, et al. Test of Station Integration Operate Software Systemin Urban Rail Transit[J]. Urban Mass Transit, 2015.

[12] Li D. Research on the Necessity of Integration Planning of Urban Rail Transit[J]. Construction \& Design for Project, 2013.

[13] Lai Y C, Ip C S. An integrated framework for assessing service efficiency and stability of rail transit systems[J]. Transportation Research Part C Emerging Technologies, 2017, 79:18-41.

[14] Wang Y, Tang T, Ning B, et al. Integrated optimization of regular train schedule and train circulation plan for urban rail transit lines[J]. Transportation Research Part E Logistics \& Transportation Review, 2017, 105:83-104. 